\title{
Sistem Penilaian Ujian Praktik SIM C Berbasis Nirkabel Menggunakan Protokol MQTT
}

\section{Scoring System of Wireless-based SIM C Practice Exam based on MQTT Protocol}

\author{
Rizki Haris Setiawan ${ }^{1, *}$, Harianto $^{2}$, Yosefine Triwidyastuti ${ }^{3}$ \\ 1,2,3 Program Studi Teknik Komputer, Institut Bisnis dan Informatika Stikom Surabaya \\ Jl. Raya Kedung Baruk No 98, Surabaya, Indonesia \\ 1,*Penulis korespondensi: rizkihariss@gmail.com, \\ ${ }^{2}$ hari@stikom.edu, ${ }^{3}$ yosefine@stikom.edu
}

Received on 07-07-2019, accepted 01-08-2019, published 06-08-2019

\begin{abstract}
Abstrak
Surat ljin Mengemudi (SIM C) adalah salah satu tanda atau bukti yang diberikan pihak kepolisian bahwa seseorang telah layak untuk mengendarai sebuah kendaraan roda dua. Pada penelitian ini penulis ingin membuat sistem penilaian ujian praktik SIM C menggunakan mikrokontroller. Peneliti mengembangkan penelitian sebelumnya yang pengiriman datanya menggunakan kabel serial menjadi pengiriman data menggunakan wireless. MQTT adalah salah satu metode pengiriman data berbasis wireless, yang menggunakan server dan klien. Dalam penelitian ini digunakan sensor getar SW-420 sebagai pendeteksi untuk setiap patok dan sensor HC-SR04 sebagai penghitung kecepatan rata-rata kendaraan. Dalam penelitian ini, ujian praktik SIM C menggunakan tiga buah lintasan yaitu keseimbangan, zig-zag dan putar balik. Dari hasil pengujian, sensor getar dapat mengirimkan data ke aplikasi ketika patok tersenggol oleh kendaraan. Sensor ultrasonik juga dapat merekam kecepatan kendaraan saat peserta melewati garis start dan menampilkan nilainya di aplikasi. Selain itu, aplikasi dapat menampilkan hasil akhir dari tiga ujian yang sudah dilakukan sebelumnya dan disimpan sementara.
\end{abstract}

Keywords: Aplikasi Sistem Penilaian, MQTT, SIM C, Wireless.

\section{Abstract}

A driver's license (SIM C) is one of the signs or evidence provided by the police that a person is fit to drive a two-wheeled vehicle. The author wants to create a SIM C practical exam scoring system using a microcontroller in this study. Researchers developed previous studies that transmit data using a serial cable into data transmission using wireless. MQTT is a wireless-based data transmission method that uses a server and a client. In this research, the SW-420 vibration sensor is used as a detector for each stake, and the HC-SR04 sensor calculates the average vehicle speed. In this study, the SIM C practice exam uses three trajectories: balance, zig-zag, and turn back. The vibration sensor can send data to the application from the test results when the peg is touched by a vehicle. Ultrasonic sensors can also record vehicle speed when participants cross the starting line and display their values in the application. In addition, the application can display the final results of the three exams that have been done previously and temporarily stored.

Keywords: MQTT, Rating System Application, SIM C, Wireless. 


\section{Pendahuluan}

Komunikasi nirkabel adalah sebuah pertukaran informasi antara dua titik tanpa hubungan langsung seperti kabel yang saling bertemu. Umumnya komunikasi nirkabel digunakan untuk mengirim informasi dari jarak jauh seperti monitoring dan sebagainya. Komunikasi nirkabel juga banyak diterapkan pada komunikasi antar perangkat yang bergerak.

Pada sistem penilaian ujian SIM C sebelumnya sistem masih menggunakan kabel sebagai komunikasi yang terhubung dari sensor-sensor sehingga cukup menyulitkan pada saat instalasi pemasangan sistem [1]. Banyaknya kabel yang tidak tertata rapi pada saat ujian juga dapat menimbulkan kerusakan karena terlindas oleh kendaraan bermotor peserta ujian.

Pada penelitian ini, penulis ingin mengembangkan sistem penilaian ujian praktik SIM C yang pengiriman datanya secara serial menjadi pengiriman data secara nirkabel agar dapat mengurangi penggunaan kabel yang terlalu banyak dan memudahkan proses instalasi pemasangan pada saat ujian praktik berlangsung. Penggunaan nirkabel pada sistem penilaian memiliki beberapa keunggulan, yaitu:

Instalasi pemasangan lebih mudah karena tidak perlu memeriksa setiap kabel yang terhubung ke sensor atau mikrokontroller.

Mengurangi resiko kabel yang rusak dikarenakan terlindas kendaraan peserta ujian.

Mengurangi penggunaan kabel yang berlebihan.

Pada penelitian ini, protokol MQTT (Message Queuing Telemetry Transport) digunakan untuk menerapkan komunikasi nirkabel pada sistem penilaian ujian praktik SIM C. MQTT adalah salah satu protokol komunikasi pesan yang ringan dan non-wired serta berbasis publish/subscribe yang dirancang khusus untuk komunikasi antar perangkat berdaya rendah.

\section{Tinjauan Pustaka}

\section{A. SIM (Surat Ijin Mengemudi)}

SIM adalah sebuah kartu identitas yang menjadi bukti bahwa pemilik kartu tersebut telah lulus ujian mengemudi kendaraan, dan dapat menggunakan kendaraan bermotor di jalan raya. Terdapat berbagai macam jenis SIM, diantaranya adalah SIM C yang diperuntukkan bagi pengendara bermotor beroda dua. Pada pengujian SIM C terdapat dua ujian yaitu ujian teori dan ujian praktik [2]. Ujian praktik SIM C dibagi menjadi tiga yaitu : Uji Lintasan Keseimbangan, Uji Lintasan Zig-zag dan Uji Lintasan U-turn / Putarbalik.

Pada proses pemberian layanan SIM, banyak dilakukan proses pengawasan oleh petugas kepolisian. Dalam proses pengawasan yang membutuhkan banyak tenaga ini sering diterapkan berbagai macam teknologi untuk membantu polisi, di antaranya adalah aplikasi untuk memeriksa legalitas SIM yang dimiliki pengemudi [3]. Aplikasi ini dapat mempercepat proses pembuatan SIM baru maupun perpanjangan SIM.

Pada penelitian sebelumnya juga telah dibuat sebuah sistem otomatis yang mampu menilai kelulusan peserta ujian praktik SIM C yang mampu membantu polisi dalam mengawasi ujian praktik [1]. Sistem penilaian ini menggunakan sensor getar yang dipasang pada setiap patok uji lintasan. Kelulusan peserta ditentukan berdasarkan kondisi semua patok pada uji lintasan. Jika ada nilai sensor getar yang berlebihan, maka patok diartikan tersenggol atau terjatuh oleh kendaraan peserta ujian, sehingga peserta dapat dinyatakan tidak lulus. Namun, sistem penilaian tesebut masih terhubung menggunakan kabel serial untuk mendapatkan data getaran setiap patok.

\section{B. Sensor Getar SW-420}

Pada penelitian ini dan penelitian sebelumnya menggunakan sensor getar yang sama, yaitu sensor getar SW-420 [1]. Sensor getar adalah suatu alat yang berfungsi untuk mendeteksi adanya getaran dan mengubahnya ke dalam sinyal listrik. Sensor ini merupakan sensor getar digital yang akan bernilai $H I G H$ pada saat menerima getaran. Cara kerja dari sensor sw-420 adalah sama seperti switch. Ketika pada kondisi tanpa getaran atau normal, sensor akan mati (normally closed). Saat sensor menerima getaran, saklar pada sensor akan membuka [4]. Sensitivitas dari sensor getar SW-420 diatur menggunakan potensiometer (variable resistor) yang dapat diputar pada sensor ini. 


\section{Wemos D1 Mini}

Wemos D1 Mini merupakan sebuah mikrokontroller yang sudah built-in dengan modul ESP-8266. Koneksi Wi-Fi (Wireless Fidelity) yang terdapat dalam modul ESP-8266 memungkinkan Wemos untuk dapat berkomunikasi dengan mikrokontroler atau komputer lain secara nirkabel. Wemos memiliki 11 pin input/output, dengan daya antara 3.3v - 5v. Dengan bentuknya yang relatif kecil dan sudah terdapat modul wifi, sehingga banyak pengguna yang menggunakan wemos sebagai penerapan untuk Internet of Things, di antaranya monitoring suara lalu lintas jalan [5] ataupun kesehatan manusia [6]. Untuk pemrograman, Wemos sama seperti Arduino yaitu menggunakan Arduino IDE. Arduino IDE itu sendiri adalah sebuah program open-source yang dapat diunduh melalui internet. Pemrograman Arduino IDE menggunakan Bahasa C [7].

\section{MQTT (Message Queuing Telemetry Transport)}

Message Queue Telemetry Transport (MQTT) adalah sebuah protokol yang digunakan untuk berkomunikasi machine to machine (M2M) yang berada pada lapisan aplikasi. MQTT bersifat lightweight yang artinya dapat berkomunikasi mengirimkan pesan dengan ukuran header yang kecil (minimum 2 bytes) untuk setiap jenis data, Hal ini memungkinkan protokol dapat bekerja di lingkungan yang terbatasnya sumber daya listrik dan kecilnya bandwidth. Protokol ini adalah jenis protokol data-agnostic yang artinya bisa mengirimkan data apapun seperti data binary, teks bahkan XML ataupun JSON. Salah satu penelitian yang menggunakan protokol MQTT adalah sistem kendali untuk monitoring rumah [8]-[9].

Pada proses komunikasi MQTT terdapat dua bagian yaitu broker dan client. Bagian client juga dibagi menjadi dua yaitu publisher dan subscriber. Publisher merupakan client yang ditugaskan untuk mengirim data ke topik yang sudah ditentukan, sedangkan subscriber adalah client yang ditugaskan untuk menerima data yang dikirim oleh publisher ke topik yang sudah ditentukan [10].

\section{Metode Penelitian}

Perancangan secara keseluruhan sistem penilaian ujian praktik SIM C dapat dilihat pada Gambar 1. Berikut adalah alur dari diagram blok:

1. Sensor Getar SW-402 yang tersambung pada Mikrokontroller Wemos D1 Mini berfungsi sebagai pendeteksi apakah tiang pembatas/patok terjatuh atau tersenggol.

2. Sensor Ultrasonik HC-SR04 yang tersambung ke Mikrokontroller Wemos D1 Mini berfungsi sebagai penghitung kecepatan pada Sistem Penilaian.

3. Raspberry Pi 3 sebagai broker/server yang bertugas menerima data dari Wemos dan mengirim data ke aplikasi.

4. Wemos D1 Mini merupakan Mikrokontroller utama yang berfungsi menerima data dari sensor getar ataupun sensor ultrasonik yang kemudian dikirim ke broker/server Raspberry Pi 3.

5. Sistem penilaian merupakan program aplikasi yang dibuat di Microsoft Visual Studio 2017 menggunakan bahasa Visual Basic .NET.

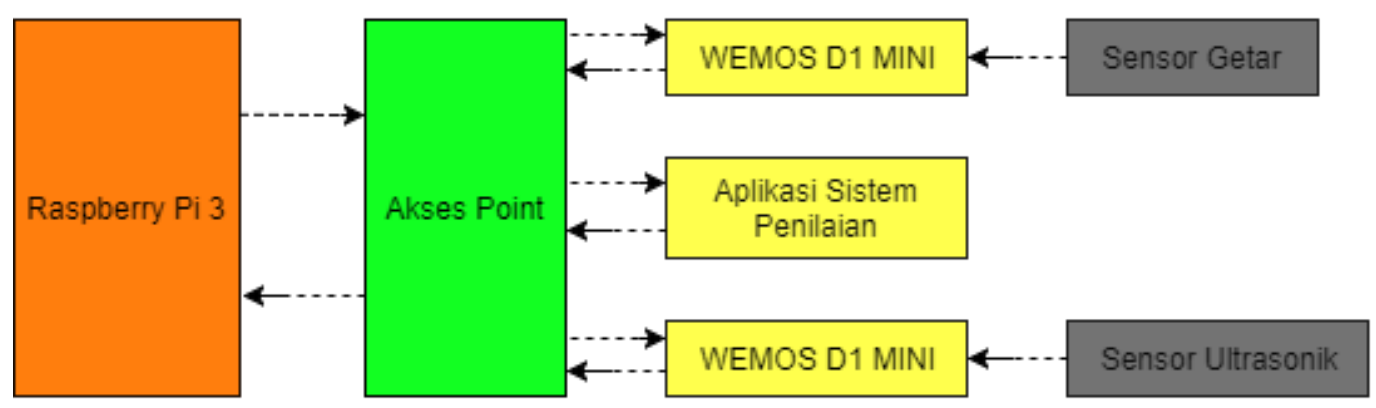

Gambar 1. Blok Diagram Sistem 


\section{Flowchart Sistem Secara Keseluruhan}

Perancangan sistem ini menggunakan bahasa pemrograman Visual Basic .Net untuk pembuatan aplikasi pada laptop / PC, sedangkan untuk pembuatan program pada pendeteksi getaran dan pendeteksi kecepatan kendaraan peserta pada patok tiang pembatas menggunakan Arduino IDE. Aplikasi pada laptop hanya menampilkan hasil dari data yang diterima dari Wemos D1 mini. Gambar 2 adalah flowchart dari sistem secara keseluruhan.

Proses dari flowchart Gambar 2 adalah sebagai berikut :

1. Insialisasi adalah proses menyambungkan ke Akses Point dan menyambungkan ke broker / server pada Raspberry Pi 3.

2. Sistem memulai dengan men-subscribe / mem-publish ke topik yang telah ditentukan.

3. Setelah itu sensor ultrasonik mendeteksi adanya pergerakan di garis start.

4. Ketika patok tiang pembatas tersenggol, aplikasi sistem menerima data dari Wemos dan menampilkannya.

5. Sensor ultrasonik yang kedua berada di garis finish dan mendeteksi adanya gerakan ketika pengendara melewati garis.

6. Data dikeluarkan melalui tampilan pada aplikasi berupa kecepatan kendaraan dan patok yang tersenggol sebelumnya.

7. Sistem selesai dengan meng-unsubscribe topik-topik yang sama seperti sebelumnya, agar tidak terjadi kekacuan pada pengiriman data.

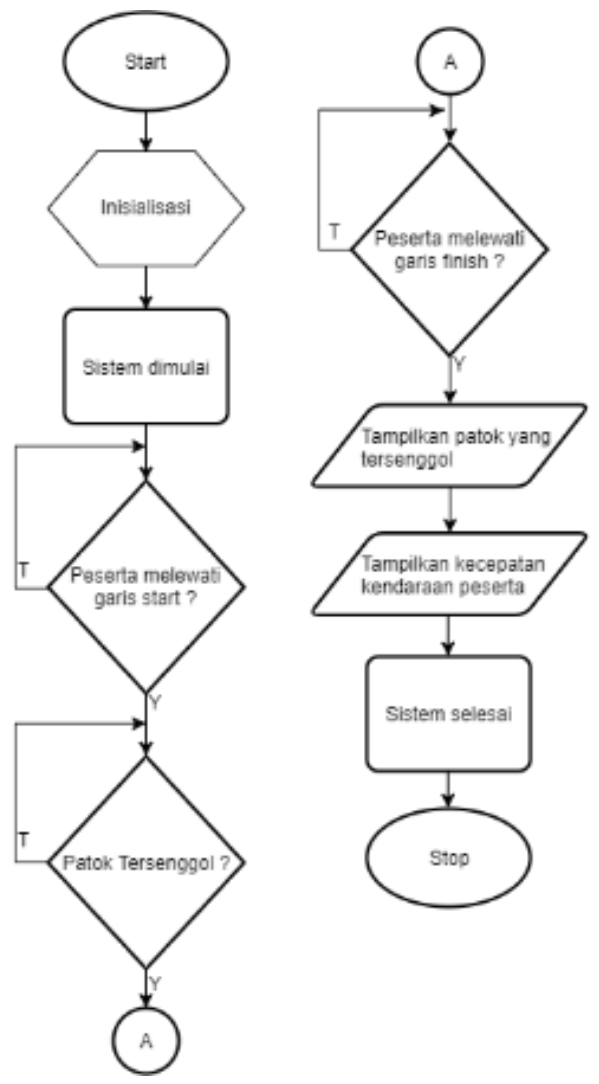

Gambar 2. Flowchart Sistem Secara Keseluruhan 


\section{Rangkaian Sensor Getar SW-420 pada Patok Tiang Pembatas}

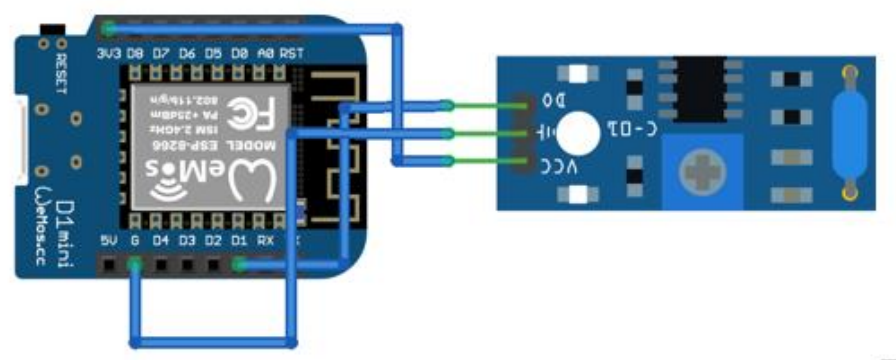

Gambar 3. Rangkaian Sensor Getar SW-420

Proses dari algoritma flowchart Gambar 4 untuk rangkaian sensor getar Gambar 3 adalah sebagai berikut:

1. Inisialisasi adalah proses menyiapkan nama ssid, password, alamat broker, nama client dan pin yang digunakan untuk Sensor Getar.

2. Setelah proses inisilalisasi, Wemos menjalankan void setup() yang dijalankan tepat satu kali saat pertama kali Wemos dinyalakan.

3. Ketika Wemos sudah tersambung ke Akses Point, Wemos akan menjalankan proses loop utama. Pembacaan sensor getar menggunakan digitalRead dimana nilai yang dihasilkan berupa 1 jika menerima data dan 0 jika tidak menerima data.

4. Setelah itu masuk ke function reconnect untuk menyambungkan ke broker.

5. Function reconnect akan terus dijalankan hingga Wemos tersambung ke broker/server. 


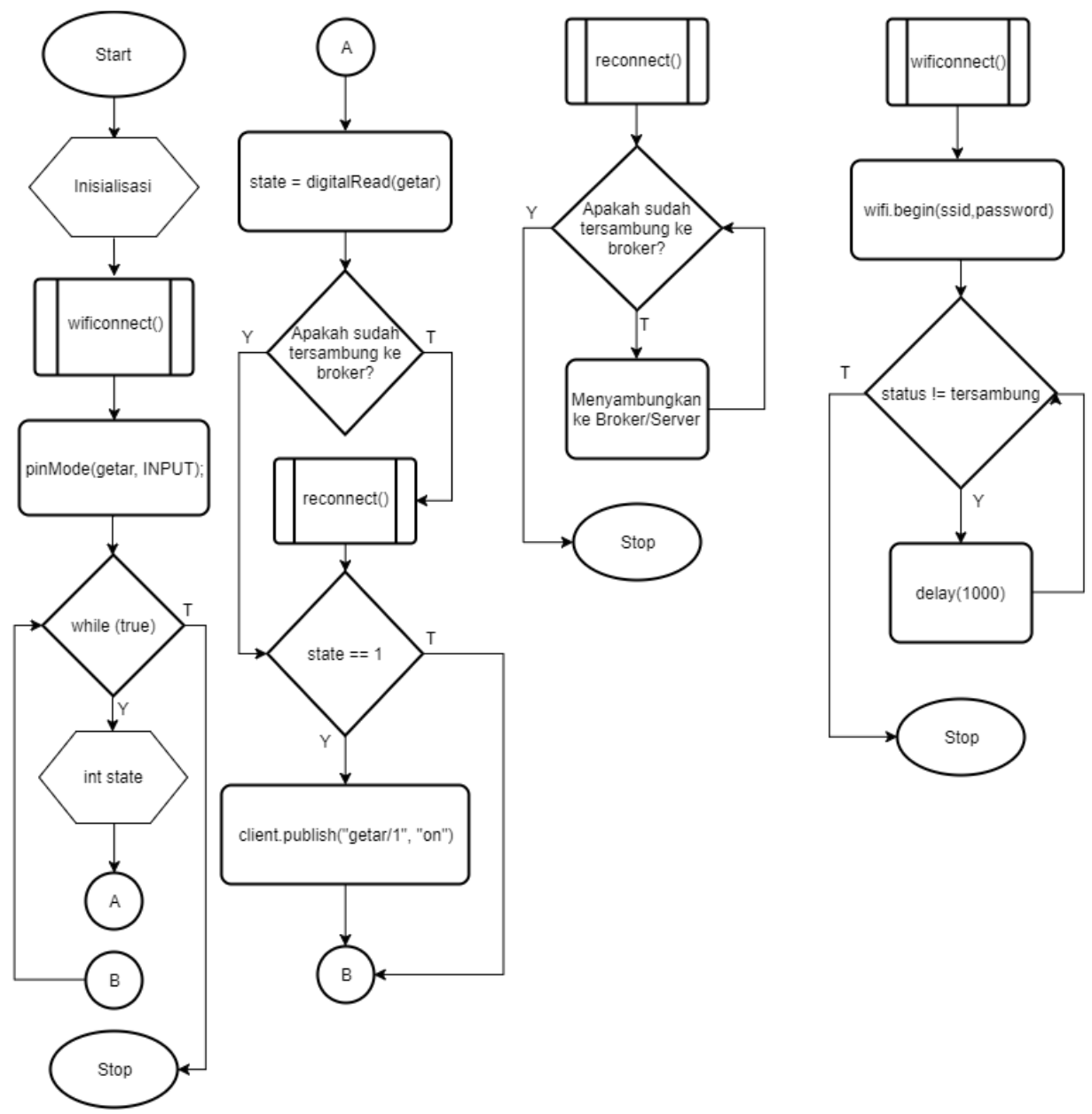

Gambar 4. Flowchart Pembacaan Data Sensor Getar

\section{Rangkaian Sensor Ultrasonik HC-SR04 pada Patok Tiang Pembatas}

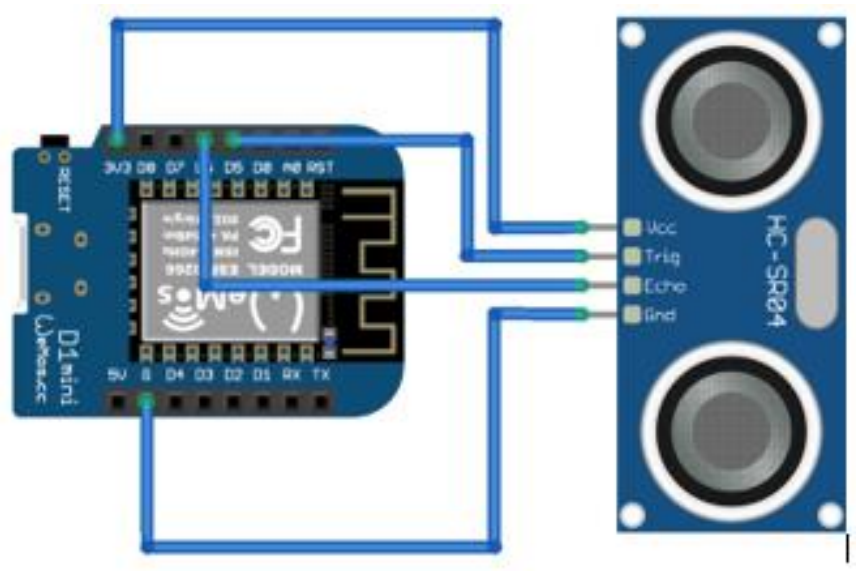

Gambar 5. Rangkaian Sensor Ultrasonik HC-SR04 


\section{Algoritma Pembacaan Data Sensor Ulrasonik HC-SR04 pada Patok Tiang Pembatas}
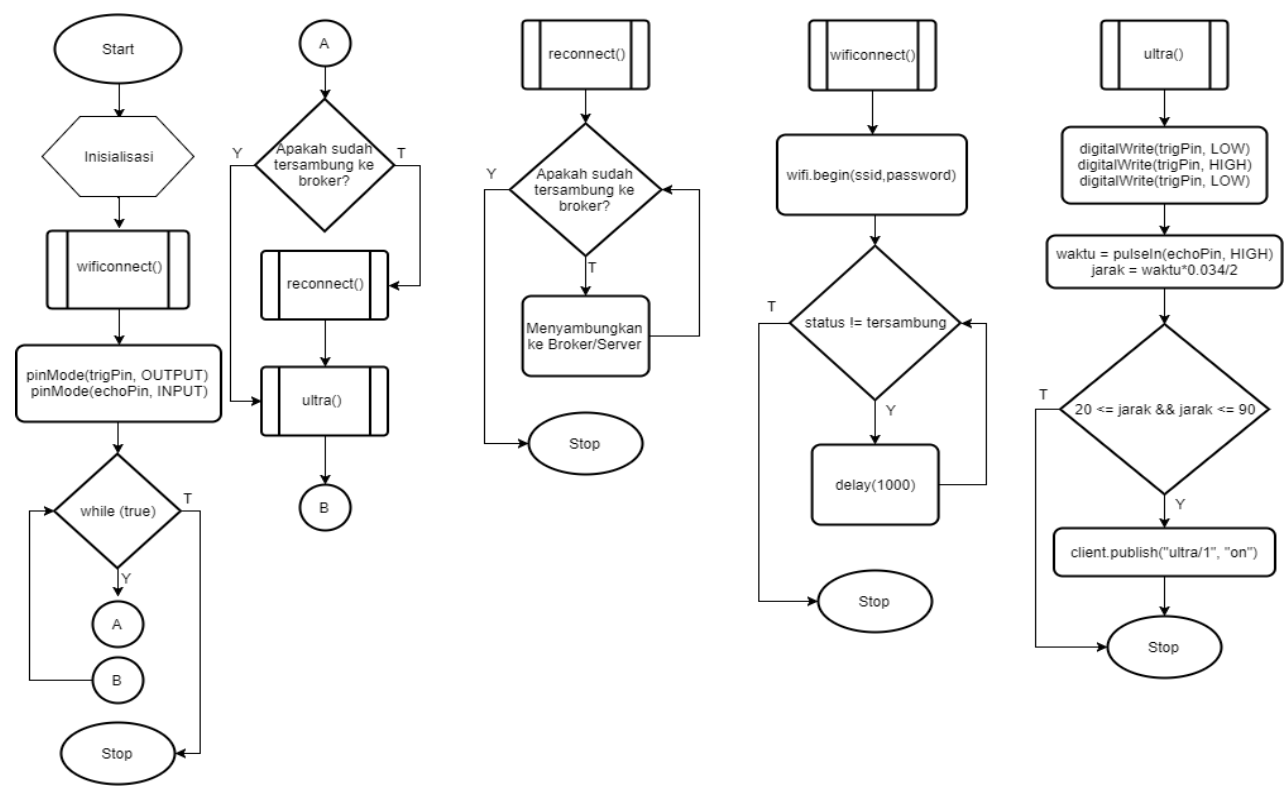

Gambar 6. Flowchart Pembacaan Data Sensor Ultrasonik

Proses dari flowchart Gambar 6 untuk rangkaian sensor ultrasonik Gambar 5 adalah sebagai berikut:

1. Inisialisasi adalah proses menyiapkan nama ssid, password, alamat broker, pin dan lain lain yang digunakan untuk Sensor Ultrasonik.

2. Setelah proses inisilalisasi, Wemos menjalankan void setup() yang dijalankan tepat satu kali saat pertama kali Wemos dinyalakan.

3. Ketika Wemos sudah tersambung ke Akses Point, Wemos akan menjalankan proses loop utama, dimana terdapat pengecekan apakah Wemos sudah tersambung ke broker

4. Ketika sudah tersambung, Wemos akan menjalankan function untuk sensor ultrasonik.

5. Pada fungsi reconnect terdapat perulangan untuk cek kondisi sudah tersambung ke broker atau belum.

6. Setelah Akses Point dan broker/server tersambung, Wemos akan menunggu data dari Sensor Ultrasonik.

\section{E. Perancangan Komunikasi pada Sistem}

Mikrokontroller yang digunakan pada sistem adalah Wemos D1 Mini, dan broker/server menggunakan Raspberry Pi 3. Kedua perangkat ini diharuskan tersambung pada satu jaringan yang sama agar dapat berkomunikasi seperti pada Gambar 7. Pada sistem ini menggunakan protokol MQTT untuk proses pengiriman dan penerimaan data.

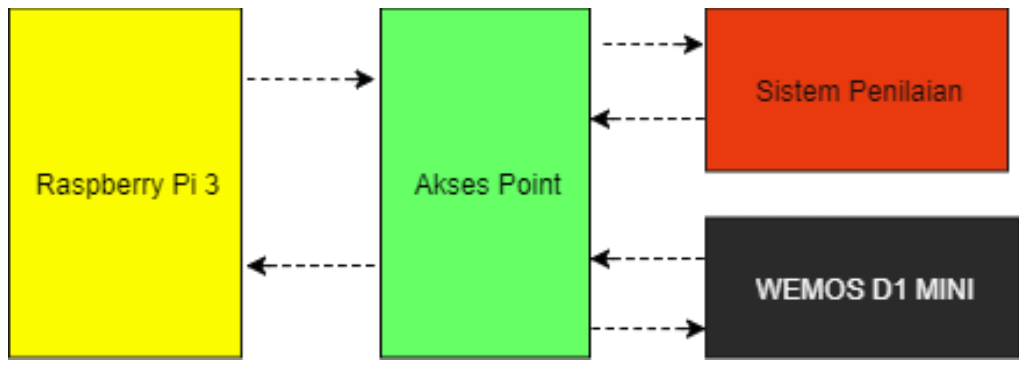

Gambar 7. Skema Jalur Koneksi Sistem 
Apabila Wemos tidak dapat menjangkau akses point dikarenakan terlalu jauh dari radius jaringan, maka terdapat beberapa solusi yang penulis dapat lakukan diantaranya.

1. Menambahkan akses point lagi dari router utama seperti pada Gambar 8. Hal ini dilakukan agar Wemos dan sistem tetap dapat tersambung pada satu jaringan dan dapat berkomunikasi.

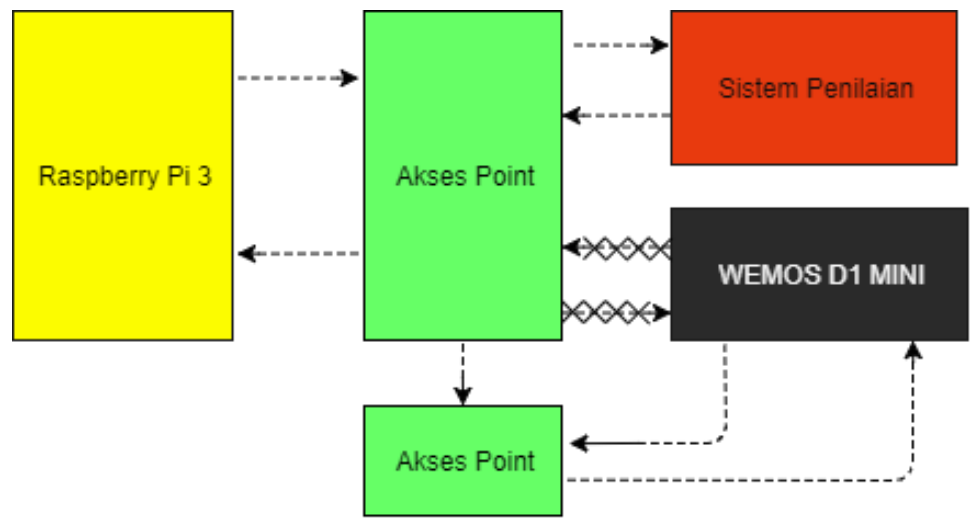

Gambar 8. Skema Jalur Koneksi Sistem dengan AP Tambahan

2. Menambahkan antena eksternal.

\section{F. Perhitungan Kecepatan pada Uji Keseimbangan dan Uji Zig-Zag}

Perhitungan kecepatan kendaraan peserta ujian hanya terdapat pada form uji keseimbangan dan uji zigzag, karena hanya pengujian tersebut yang membutuhkan kecepatan dari kendaraan peserta. Setelah data awal dan data akhir terkumpul, program akan mencari selisih dari waktu awal dan waktu akhir menggunakan rumus (1). Kemudian perhitungan kecepatan kendaraan menggunakan rumus (2), dengan jarak lintasan 12 meter.

Waktu tempuh $=$ waktu akhir - waktu awal

Kecepatan $=\frac{\text { Jarak lintasan }}{\text { Waktu tempuh }}$

\section{G. Perancangan Patok Tiang Pembatas Sensor Getar dan Sensor Ultrasonik}

Berdasarkan syarat sarana patok untuk ujian praktik, maka pembatas/patok dirancang seperti pada Gambar 9.
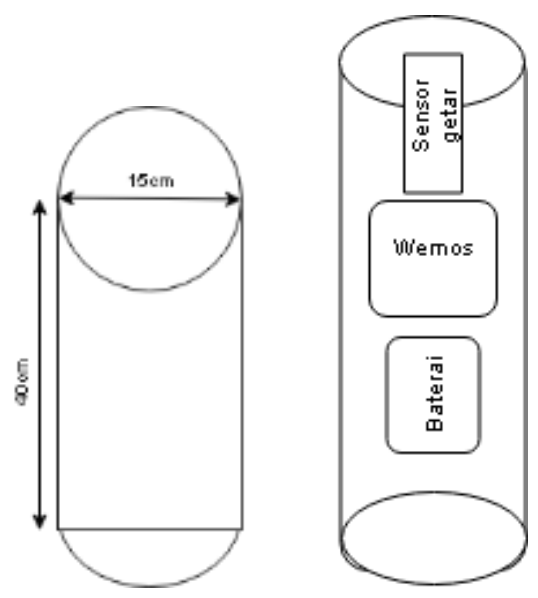

Gambar 9. Perancangan Patok Tiang Pembatas Sensor Getar

Seperti pada Gambar 9, tiang pembatas sensor getar memiliki tinggi $40 \mathrm{~cm}$ dan diameter antara 10-15 $\mathrm{cm}$. Didalam patok terdapat Wemos, Sensor getar, dan Baterai. Sensor terhubung ke Wemos dan mendapat daya dari baterai kurang lebih 5V. Tiang pembatas/patok yang digunakan untuk sensor ultrasonik memiliki 
dimeter $15 \mathrm{~cm}$ dan tinggi $40 \mathrm{~cm}$ sama seperti patok/pembatas sensor getar dan dapat dilihat pada Gambar 10 .

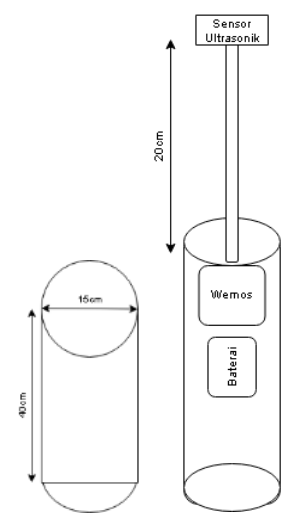

Gambar 10. Desain Patok/tiang Pembatas Sensor Ultrasonik

\section{Hasil Pengujian dan Pembahasan}

\section{A. Pengujian Sensor Getar SW-420}

Tujuan dari pengujian ini adalah untuk mengatur sensitifitas dari sensor getar dan mengetahui apakah sensor bekerja dengan baik atau tidak. Indikator keberhasilannya adalah dapat mengeluarkan karakter " 1 " ketika tersenggol dan "0" ketika tidak tersenggol. Pada Sensor Getar SW-420 terdapat variabel resistor yang dapat diatur untuk mengatur sensitifitas dari sensor getar. Putaran berlawanan dengan arah jarum jam dapat membuat Sensor menjadi semakin sensitif dan putaran dengan arah jarum jam dapat membuat Sensor menjadi semakin tidak sensitif. Dapat dilihat pada Gambar 11, ketika Sensor tidak menerima getaran maka akan memberi nilai " 0 " sedangkan ketika Sensor menerima getaran maka akan memberi nilai "1" seperti pada Gambar 12. Keluaran dari Sensor Getar SW-420 merupakan data Digital sehingga hanya dapat mengeluarkan "0" atau " 1 ".

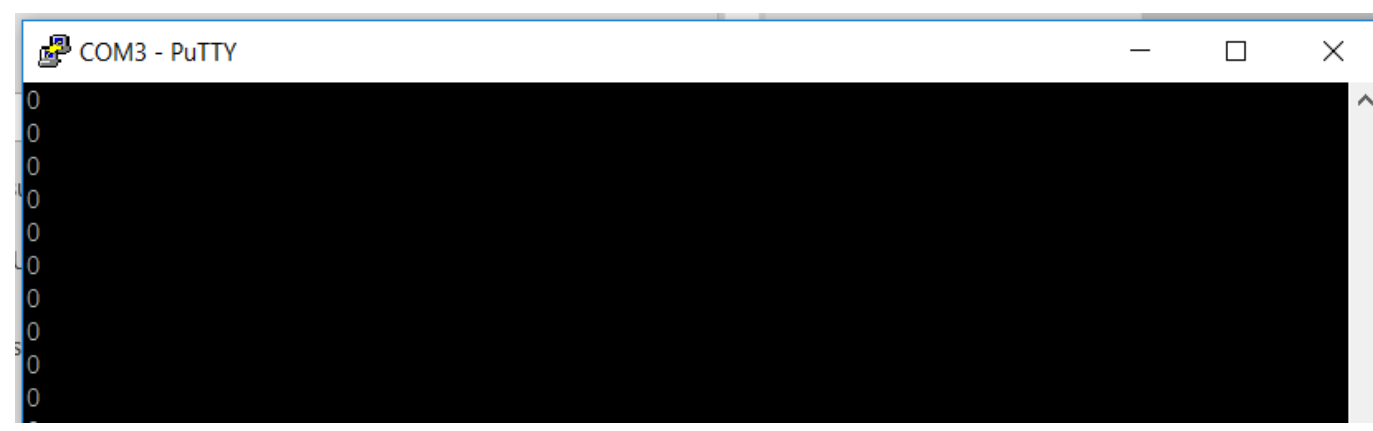

Gambar 11. Ketika Sensor Tidak Menerima Getaran

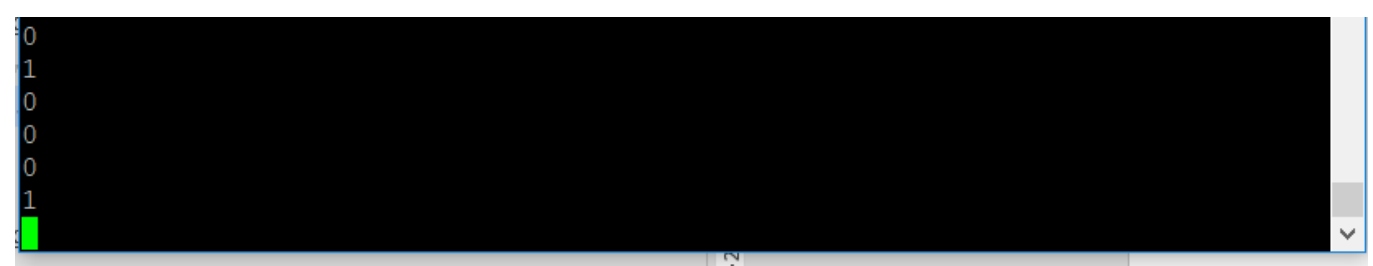

Gambar 12. Ketika Sensor Menerima Getaran 


\section{B. Pengujian Pengukur Kecepatan pada Lintasan Uji Keseimbangan}

Pengujian ini untuk mengetahui apakah data dari sensor telah berhasil dikirim ke broker/server. Indikator keberhasilannya adalah sensor ultrasonik dapat menjalankan proses perhitungan waktu dan mengkalkulasi berapa kecepatan kendaraan peserta ujian. Raspberry pi 3 sebagai broker dan laptop dengan aplikasi sistem penilaian sebagai client.

Gambar 13 merupakan hasil uji coba dari pengujian kecepatan pada aplikasi dan stopwatch di handphone. Tabel 1 merupakan hasil uji coba pengujian kecepatan. Dari pengujian tersebut dapat disimpulkan pengukuran kecepatan kendaraan berjalan dengan baik.

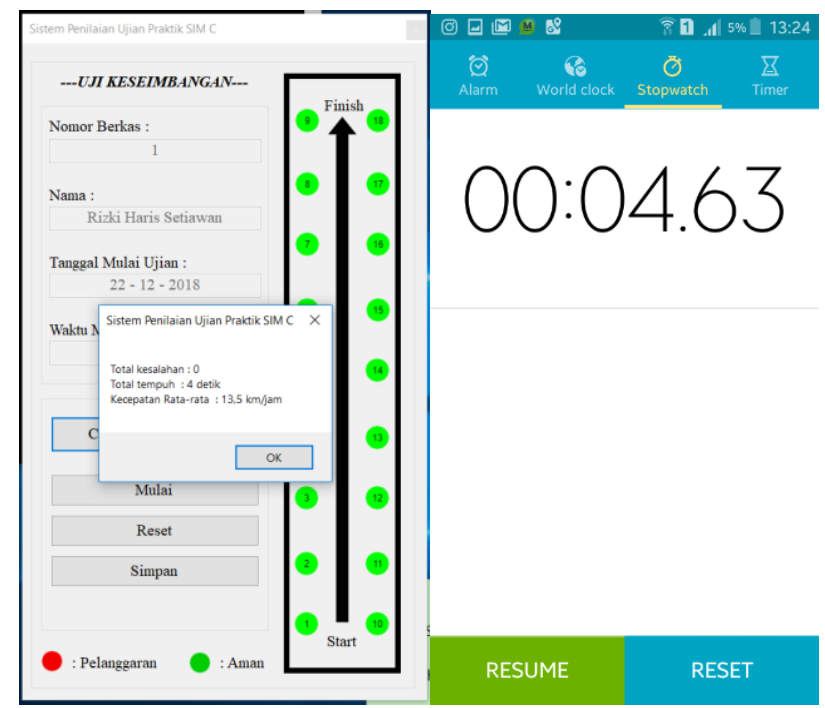

Gambar 13. Percobaan pada Aplikasi (kiri) dan Stopwatch pada Handphone (kanan)

Tabel 1 Percobaan Pengukuran Kecepatan

\begin{tabular}{ccccccc}
\hline No & Waktu Awal & Waktu Akhir & Waktu Tempuh & Stopwatch & Jarak & $\mathbf{K m} / \mathbf{h}$ \\
\hline 1 & $13: 09: 40$ & $13: 09: 45$ & 5 detik & $00: 05: 70$ & $15 \mathrm{~m}$ & 10.8 \\
2 & $13: 12: 20$ & $13: 12: 25$ & 5 detik & $00: 05: 25$ & $15 \mathrm{~m}$ & 10.8 \\
3 & $13: 14: 20$ & $13: 14: 29$ & 9 detik & $00: 09: 41$ & $15 \mathrm{~m}$ & 6 \\
4 & $13: 16: 34$ & $13: 16: 38$ & 4 detik & $00: 04: 00$ & $15 \mathrm{~m}$ & 13.5 \\
5 & $13: 20: 31$ & $13: 20: 34$ & 3 detik & $00: 03: 17$ & $15 \mathrm{~m}$ & 18 \\
6 & $13: 23: 19$ & $13: 23: 23$ & 4 detik & $00: 04: 63$ & $15 \mathrm{~m}$ & 13.5 \\
7 & $13: 25: 30$ & $13: 25: 34$ & 4 detik & $00: 04: 48$ & $15 \mathrm{~m}$ & 13.5 \\
8 & $13: 27: 07$ & $13: 27: 13$ & 6 detik & $00: 06: 13$ & $15 \mathrm{~m}$ & 9 \\
9 & $13: 28: 34$ & $13: 28: 40$ & 6 detik & $00: 06: 43$ & $15 \mathrm{~m}$ & 9 \\
10 & $13: 29: 52$ & $13: 29: 01$ & 9 detik & $00: 09: 47$ & $15 \mathrm{~m}$ & 6 \\
\hline
\end{tabular}

\section{Pengujian Delay Pengiriman Data Client ke Broker}

Tujuan dari pengujian ini adalah menemukan jarak yang efektif dalam pengiriman data dari Wemos ke broker. Indikator keberhasilannya adalah menemukan jarak yang efektif agar dapat diterima oleh Broker. Akses point diletakkan pada jarak-jarak tertentu seperti pada Tabel 2. Kemudian sebuah objek diletakkan tepat di depan masing-masing Patok Ultrasonik. Dengan demikian cmd console pada setiap patok akan berulang-ulang mengirimkan pesan yang menandakan bahwa sebuah objek terdeteksi. 
Tabel 2 Hasil Pengujian dengan AP Andromax M2y

\begin{tabular}{cccc}
\hline No. & Jarak & Ultra1 & Sensor \\
& & Ultra2 \\
\hline 1. & $2 \mathrm{~m}$ & $0 \mathrm{~s}$ & $0 \mathrm{~s}$ \\
2. & $4 \mathrm{~m}$ & $0 \mathrm{~s}$ & $0 \mathrm{~s}$ \\
3. & $6 \mathrm{~m}$ & $0 \mathrm{~s}$ & $0 \mathrm{~s}$ \\
4. & $8 \mathrm{~m}$ & $0 \mathrm{~s}$ & $0 \mathrm{~s}$ \\
5. & $10 \mathrm{~m}$ & $0 \mathrm{~s}$ & $0 \mathrm{~s}$ \\
6. & $12 \mathrm{~m}$ & $1 \mathrm{~s}$ & $1 \mathrm{~s}$ \\
7. & $14 \mathrm{~m}$ & Tidak Terjangkau & Tidak Terjangkau \\
8. & $16 \mathrm{~m}$ & Tidak Terjangkau & Tidak Terjangkau \\
9. & $18 \mathrm{~m}$ & Tidak Terjangkau & Tidak Terjangkau \\
\hline
\end{tabular}

Tabel 2 merupakan hasil ujicoba dari pengujian delay penerimaan kecepatan pada sensor ke aplikasi. Dari Tabel 2 dapat diketahui bahwa pada jarak 12 meter, pengiriman data sudah menghasilkan delay pada proses pengirimannya. Sedangkan pada jarak lebih dari 12 meter, patok sudah tidak dapat mengirimkan data dengan normal.

\section{Pengujian Lintasan Uji pada Aplikasi Secara Keseluruhan}

Tujuan dari pengujian ini adalah untuk menguji apakah patok-patok sudah terhubung dengan aplikasi penilaian dan aplikasi secara keseluruhan dapat berjalan dengan baik. Raspberry Pi 3 digunakan sebagai broker dan laptop dengan aplikasi sistem penilaian sebagai client.

Percobaan pada Tabel 3, Tabel 4, dan Tabel 5 menggunakan beberapa skenario sebagai berikut:

a. Kendaraan jalan lurus tanpa menabrak patok / tiang pembatas.

b. Kendaraan jalan lurus tanpa menabrak patok dekat dengan patok sebelah kiri dengan jarak $10 \mathrm{~cm}$.

c. Kendaraan jalan lurus tanpa menabrak patok dekat dengan patok sebelah kanan dengan jarak $10 \mathrm{~cm}$.

d. Kendaraan jalan lurus dan menyenggol patok namun tidak terjatuh.

e. Kendaraan jalan lurus dan menyenggol patok hingga jatuh.

Tabel 3 Pengujian Uji Keseimbangan

\begin{tabular}{cccc}
\hline Skenario & Kecepatan & Target & Hasil \\
\hline $\mathrm{a}$ & $6 \mathrm{Km} / \mathrm{h}$ & 0 pelanggaran & sesuai \\
$\mathrm{b}$ & $10.8 \mathrm{Km} / \mathrm{h}$ & 0 pelanggaran & sesuai \\
$\mathrm{c}$ & $9 \mathrm{Km} / \mathrm{h}$ & 0 pelanggaran & sesuai \\
$\mathrm{d}$ & $7.2 \mathrm{Km} / \mathrm{h}$ & $1,5,8,17$ pelanggaran & Sesuai \\
$\mathrm{e}$ & $9 \mathrm{Km} / \mathrm{h}$ & $1,5,8,17$ pelanggaran & Tidak sesuai \\
\hline
\end{tabular}

Tabel 4 Pengujian Uji Zig-Zag

\begin{tabular}{cccc}
\hline Skenario & Kecepatan & Target & Hasil \\
\hline $\mathrm{a}$ & $1 \mathrm{Km} / \mathrm{h}$ & 0 pelanggaran & sesuai \\
$\mathrm{b}$ & $2.4 \mathrm{Km} / \mathrm{h}$ & 0 pelanggaran & sesuai \\
$\mathrm{c}$ & $1.2 \mathrm{Km} / \mathrm{h}$ & 0 pelanggaran & sesuai \\
$\mathrm{d}$ & $1.41 \mathrm{Km} / \mathrm{h}$ & $4,6,8$ pelanggaran & Sesuai \\
$\mathrm{e}$ & $2 \mathrm{Km} / \mathrm{h}$ & $4,6,8$ pelanggaran & Tidak sesuai \\
\hline
\end{tabular}

Tabel 5 Pengujian Uji Putar balik

\begin{tabular}{ccc}
\hline Skenario & Target & Hasil \\
\hline $\mathrm{a}$ & 0 pelanggaran & sesuai \\
$\mathrm{b}$ & 0 pelanggaran & sesuai \\
$\mathrm{c}$ & 0 pelanggaran & sesuai \\
$\mathrm{d}$ & $1,4,8,10$ pelanggaran & Sesuai \\
$\mathrm{e}$ & $1,4,8,10$ pelanggaran & Tidak sesuai \\
\hline
\end{tabular}


Dari percobaan diatas dengan beberapa skenario maka dapat disimpulkan : uji keseimbangan memiliki $80 \%$ tingkat keberhasilan, uji zig-zag $80 \%$ tingkat keberhasilan dan uji putar baik $80 \%$ tingkat keberhasilan. Pada gambar 14, dapat diketahui bahwa Patok Sensor Getar dan Patok Sensor Ultrasonik dapat berkomunikasi dengan Aplikasi. Aplikasi dapat menampilkan Total pelanggaran dan Kecepatan rata-rata dari kendaraan peserta pada Lintasan Keseimbangan dan Zig-zag.

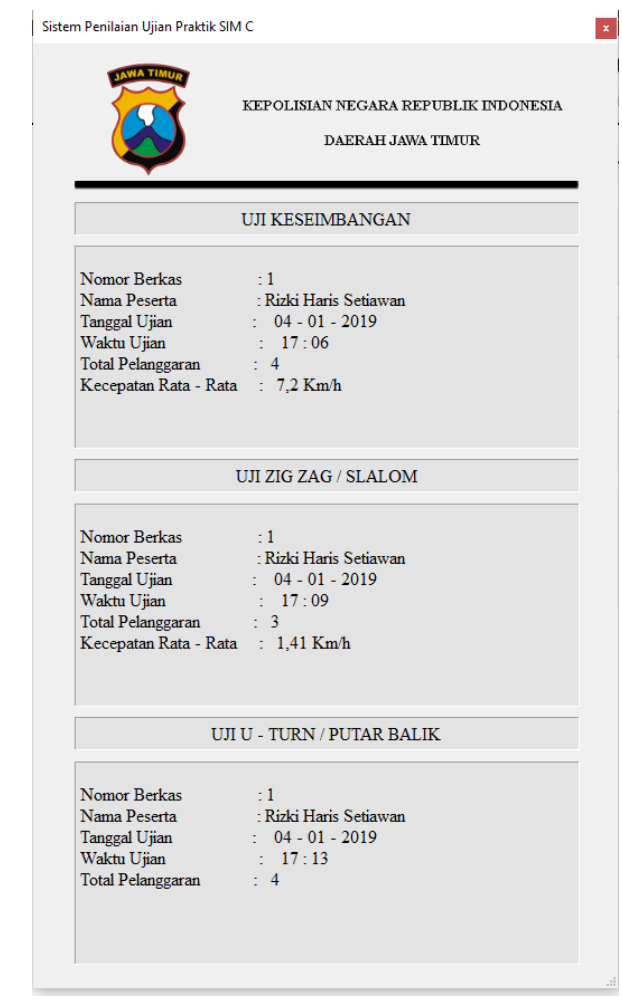

Gambar 14. Hasil Akhir Pengujian pada Aplikasi

\section{KESIMPULAN}

Berdasarkan hasil pengujian diperoleh hasil bahwa aplikasi penilaian ujian praktik SIM C dapat berkomunikasi dengan setiap Wemos D1 Mini yang ada pada patok dan dapat menampilkan pelanggaran pada patok/tiang pembatas yang terjatuh/tersenggol. Aplikasi penilaian ujian praktik SIM C juga dapat menghitung dan menampilkan kecepatan kendaraan peserta pada uji keseimbangan dan uji zig-zag. Namun, pengiriman setiap data pada patok bergantung pada jarak antara patok dengan akses point, dimana pada jarak lebih dari 12 meter patok sudah tidak dapat mengirimkan data dengan normal.

\section{DAFTAR Pustaka}

[1] Siahaan, O.A., 2017. Rancang Bangun Aplikasi Penilaian Ujian Praktik SIM C Berbasis Arduino Mega2560, JCONES Vol 6, No 2 .

[2] Jaya, M.P. 2017. Mekanisme Pelayanan Surat Izin Mengemudi di Kepolisian Resort Kota Bontang. eJournal Administrasi Negara. Vol. 5, No. 4.

[3] Suryani, D., Yulianti, A., dan Zulhelmi, M. 2018. Aplikasi Legalitas Surat Izin Mengemudi (SIM) Berbasis Mobile (Studi Kasus: Polisi Resort Rengat). IT Journal Research and Development. Vol. 2, No. 2.

[4] Theorycircuit. SW-420 Vibration Sensor Arduino Interface. http://www.theorycircuit.com/sw-420-vibration-sensor-arduinointerface. Diakses tanggal 7 November 2018.

[5] Alsina-Pages, R.M., Hernandez-Jayo, U., Alias, F., dan Angulo, I. 2017. Design of a Mobile Low-Cost Sensor Network Using Urban Buses for Real-Time Ubiquitous Noise Monitoring. Sensors, Vol. 17.

[6] Ciuffoletti, A. 2019. Design of an Open Remote Electrocardiogram (ECG) Service. Future Internet, Vol. 11.

[7] Jainrk, Instructables Circuits. Programming the ESP8266 WeMos-D1R2 Using Arduino Software / IDE. https://www.instructables.com/id/Programming-the-WeMos-Using-Arduino-SoftwareIDE. Diakses tanggal 8 Oktober 2018. 
RIZKI HARIS SETIAWAN, DKK:

JTECE. VOL. 01, NO. 02, PP.113-125, JULI 2019

[8] Rochman, H.A., Primananda, R., dan Nurwasito, H. 2017. Sistem Kendali Berbasis Mikrokontroler Menggunakan Protokol MQTT pada Smart Home. Jurnal Pengembangan Teknologi Informasi dan Ilmu Komputer, Vol. 1, No. 6.

[9] Uphadhyay, Y. 2016. MQTT Based Secure Home Automation System. Symposium on Colossal Data Analysis and Networking (CDAN).

[10] Thangavel, D., Ma, X., Valera, A., Tan, H-X., dan Tan, C. K-Y. 2014. Performance Evaluation of MQTT and CoAP via a Common Middleware. IEEE Ninth International Conference on Intelligent Sensors, Sensor Networks and Information Processing (ISSNIP). 21-24 April. 